\title{
An Integrated ICT Management Framework for Commercial Banking Organisations in South Africa
}

\author{
Simon Mukenge Tshinu \\ Tshwane University of \\ Technology, South Africa
}

mukengespierre@yahoo.com

\author{
Gerrit Botha \\ Tshwane TechnoCentre, \\ South Africa
}

gerrit@ditm.co.za

\section{Prof. Marlien Herselman \\ Tshwane University of Technology, South Africa}

\author{
herselmanme@tut.ac.za
}

\begin{abstract} structure through an integrated ICT Management Framework. agement practices for better management of ICT infrastructure.

Material published as part of this publication, either on-line or in print, is copyrighted by the Informing Science Institute. Permission to make digital or paper copy of part or all of these works for personal or classroom use is granted without fee provided that the copies are not made or distributed for profit or commercial advantage AND that copies 1) bear this notice in full and 2) give the full citation on the first page. It is permissible to abstract these works so long as credit is given. To copy in all other cases or to republish or to post on a server or to redistribute to lists requires specific permission and payment of a fee. Contact Publisher@InformingScience.org to request redistribution permission.
\end{abstract}

This article explores the possibility of integrating some of the most referenced ICT Management Frameworks in managing ICT infrastructure in the banking sector. This was done by identifying core components that it should address and the related frameworks that need to be applied at each component. In this context, this article is also prompting further research in managing ICT infra-

Information and Communication Technology (ICT) infrastructure needs to be regarded as the integration of different components that interact with one another directly and indirectly for sustainability of organisation's objectives. For the organisations that rely intensely on ICT, such as in the banking industry, it is a necessity to develop practices and tools such as integrated ICT Management Framework that collect best practices found in different ICT Management Frameworks and combine them to business objectives that direct ICT strategies, technologies, and man-

This research was conducted by applying the qualitative research method and interviews as a technique for the collection of data from participants. It was found that the ICT Management Framework is not a new topic in the South African banking industry, but its application is a subject matter which every individual bank applies according to their requirements. Banks in SA in general do not address the question of integrating frameworks and indirect components that con-

tribute to the success of ICT applications in the framework.

Keywords: ICT management framework, ICT management, banking organisation, ITIL, COBIT, CMM, ISO 17799. 


\section{Introduction}

According to Araya, Chaparo, Orero and Joglar (2007) and Cordis (2007), the integrative view on ICT infrastructure refers to the inclusion of elements that directly deal with ICT and organisation such as direct ICT human resources, ICT technological infrastructure, ICT proprietary resources (protected patent, and copyright), and ICT budget. Indirect resources include personnel outside ICT department as management, culture of the organisation and its structure, relationship with business partners, and budget outside the ICT department that provides training for employees in general. All these resources combined, not only direct resources but also other resources, sustain the success of ICT with the organisation and contribute to the competitive advantage of the organisation.

Lucas (2005, p. 5) mentions that the key to success with technology is not the technology per se but the ability to manage it well. The same is the view of Caruso (2003), with emphasis on the implementation of security policy to safeguard IT infrastructure. Concerning the management of ICT infrastructure, many tools have been developed including the use of different best practices presented in frameworks such as Information Technology Infrastructure Library (ITIL), Control Objectives for Information and Related Technology (COBIT), Capability Maturity Model (CMM), and International Organisation for Standardisation (ISO) 17799. These four frameworks are some of the different frameworks that incorporate useful best practices used in managing ICT infrastructures in different businesses sectors including the banking sector, which is the focus of this article.

Although many authors, including organisations, such as IT Governance Institute (2007), mention that as all frameworks complement each other, users can benefit from using the COBIT content as an overall approach to and governing IT, together with more detailed standards such as ITIL for service delivery, CMM for solution delivery, and ISO 17799 for information security. None of them, to our best knowledge, have proposed how they fit together in a single management framework that can allow a holistic view when applied to ICT management.

In this article a formal research process will be applied, which is described in the research design section. The objective was to explore the necessary components that ICT Management Frameworks needs to incorporate for better management and control of ICT infrastructure.

\section{Literature Review}

The first step in this literature review is to describe the ICT Management Framework, and then briefly provide an overview of the four frameworks.

In general, a framework is a set of beliefs, ideas, or rules that is used as the basis for making judgment and decisions (Hornby, 2000, p. 471).

An ICT Management Framework is a management tool that provides the ICT organisation with a precise guideline of best practices and proved standards that need to be addressed for successful technical, organisational, and legal management of ICT service delivery in support of business strategies and operations (Barton, 2003, p. 32; Turban, Rainer, \& Potter, 2005, p. 36; Thamhain, 2005, p. 6).

According to the IT Governance Institute (2005) the effective adoption of best practices can provide many benefits, especially in the area of advanced technology. These include:

- $\quad$ Avoiding re-inventing the wheel;

- Reducing dependency on technology experts;

- Increasing the potential to utilise less-experienced staff if properly trained; 
- Making it easier to leverage external assistance;

- Overcoming vertical silos and nonconforming behaviour;

- Reducing risks and errors;

- Improving quality;

- Improving the ability to manage and monitor;

- Increasing standardisation leading to cost reduction;

- Improving trust and confidence from management and partners;

- Creating respect from regulators and other external reviewers; and

- Safeguarding and proving value.

The organisation's need for ICT management best practices is influenced by internal and external factors. Internal factors relates to, inter alia, the need for safety of information stored on ICT infrastructures, increased productivity through reusable processes, and increased quality in managing ICT. The factors are important as just one successful security breach, theft, error, hack, or virus attack on a company's ICT can result in serious financial and reputation damage (Cordis, 2007). External factors, such as the introduction of Sarbanes-Oxley Act in the USA and King 2 Report in SA, enhance corporate governance through measures that will strengthen internal checks and balances and, ultimately, strengthen corporate accountability. Effective governance over ICT has become the law for many companies (IT Governance Institute, 2004).

A brief overview of the four frameworks is presented in Table 1, which presents each framework and its benefits to the organisation.

Table 1: ICT Management Frameworks and benefits

\begin{tabular}{|c|c|}
\hline FRAMEWORK & BENEFITS \\
\hline ITIL & $\begin{array}{l}\text { ITIL provides a systematic and professional approach to the management of } \\
\text { IT service provision. Adopting its guidance offers users a huge range of bene- } \\
\text { fits that include: } \\
\text { - } \quad \text { Reduced costs } \\
\text { - } \quad \text { Improved IT services through the use of proven best practice proc- } \\
\text { esses } \\
\text { - Improved customer satisfaction through a more professional approach } \\
\text { to service delivery } \\
\text { - Standards and guidance } \\
\text { - } \quad \text { Improved productivity } \\
\text { - } \quad \text { Improved use of skills and experience } \\
\text { - } \quad \text { Improved delivery of third party services through the specification of } \\
\text { ITIL as the standard for service delivery in services procurements } \\
\text { The current version of ITIL, which is version } 3 \text { replaces the version } 2 \text { since } \\
\text { May } 2007 \text { and is structured in the following five publications: } \\
\text { - } \quad \text { Service strategy } \\
\text { - } \quad \text { Service design } \\
\text { - } \quad \text { Service transition } \\
\text { - } \quad \text { Service operation } \\
\text { Continual service improvement }\end{array}$ \\
\hline
\end{tabular}

Source: Best Management Practice (2007). 


\begin{tabular}{|c|c|}
\hline FRAMEWORK & BENEFITS \\
\hline$C O B I T$ & $\begin{array}{l}\text { COBIT supports IT governance by providing a framework to ensure } \\
\text { that: } \\
\text { - } \text { IT is aligned with the business } \\
\text { - } \text { IT enables the business and maximises benefits } \\
\text { - } \text { IT resources are used responsibly } \\
\text { - IT risks are managed appropriately } \\
\text { - A view, understandable to management, of what IT does } \\
\text { - Clear ownership and responsibilities, based on process orienta- } \\
\text { tion } \\
\text { Shared understanding amongst all stakeholders, based on a common } \\
\text { language }\end{array}$ \\
\hline \multicolumn{2}{|c|}{ Source: IT Governance Institute (2007). } \\
\hline CMMI & $\begin{array}{l}\text { CMMI provides the following benefits: } \\
\text { - Efficient, effective assessment and improvement across multi- } \\
\text { ple process disciplines in an organisation } \\
\text { - } \\
\text { - } \\
\text { A A commonon, integrated vision of improvement for all elements } \\
\text { of an organisation } \\
\text { - A means of representing new discipline-specific information in } \\
\text { a standard, proven process improvement context }\end{array}$ \\
\hline & \\
\hline
\end{tabular}




\begin{tabular}{|c|c|}
\hline FRAMEWORK & BENEFITS \\
\hline ISO 17799 & $\begin{array}{l}\text { ISO } 17799 \text { offer an excellent framework for those developing or en- } \\
\text { hancing their organisation's security, tangible benefits are: } \\
\text { - A valuable framework for resolving security issues } \\
\text { - Enhancement of client confidence and perception of the organi- } \\
\text { sation } \\
\text { - Enhancement of business partners' confidence and perception } \\
\text { of the organisation } \\
\text { - Provides confidence that the organisation has managed risk } \\
\text { - Enhancement of security awareness within an organisation } \\
\text { - Assists in the development of best practice } \\
\text { - Can often be a deciding differentiator between competing or- } \\
\text { ganisations } \\
\text { - Better protection of the company's confidential information; } \\
\text { - Reduced risk of hacker attacks } \\
\text { - Faster and easier recovery from attack } \\
\text { - Structured security methodology that has gained international } \\
\text { recognition }\end{array}$ \\
\hline & \\
\hline
\end{tabular}

The combination of computers, databases, and telecommunications, especially the Internet, provide managers with an incredible number of options for improving the way organisations function. It is likely that technology will play a major role in the design of an organisation and the way in which it operates. As a result, management of the organisation implies the management of ICT. The key to success with technology is not the technology per se, but the ability to manage it well (Lucas, 2005, p. 5, 422).

The key to implementing an information management technology framework is to add structure to unstructured information, to address elements such as Access Controls, System Security, Storage, and Monitoring and Compliance (Blalock, 2005). Therefore, combining different best practices from various frameworks in one single framework is an option to ensure adequate management practices, especially for organisations that rely more on ICT resources such as banking organisations.

\section{Research Design}

Given the need for direct interaction with practitioners in the ICT management field, and the possibility of grasping first hand touch on what is being done by different commercial banks in relation to the use of ICT Management Frameworks, the qualitative research method was selected for the purpose of this study. This is based on the fact that information from one organisation is different from another, but all address the same concept of ICT management using ICT Management Frameworks. An exploratory research approach, which is undertaken in cases where very little is known about the research topic under study, was followed (Bless \& Higson-Smith, 2004, p. 37). 
Concerning data collection techniques, apart from reading published materials on ICT management and different frameworks, which constitute the secondary data, the selected technique for primary data collection was semi-structured interviews (including personal and mini-group interviews) that regroup together participants (two to six people) who are experts in ICT management at the same organisation to discuss the research topic.

Mentioning the advantage of using semi-structured interviews, Welman and Kruger (2005, p. 161) indicate that in the semi-structured interview the interviewer is allowed to use probes with a view to clearing up vague responses or to ask for elaboration of incomplete answers. Such probes may vary from "Why?" to "Could you elaborate on this?" The respondent may be given the necessary encouragement to proceed. It provides the opportunity to discuss with practitioners faceto-face, with the possibility of reviewing their framework on-site, clear any misunderstanding, and reordering questions to facilitate the flow of discussion and prevent any deadlock or misunderstanding that could occur.

\section{Research Participants}

For the purpose of this study, the participants included people from the four major commercial banking organisations operating in South Africa, which are represented by their senior ICT managers and employees with in-depth knowledge of ICT Management Frameworks and their application in the banking organisations. For the purpose of confidentiality, alphabetical letters (A, B, C, D) were used to represent participating organisations as presented in Table 2.

The selection of the four participating banking organisations is based on the fact that these organisations are the major commercial banks in the country; they have large banking ICT infrastructure and have more concern about the management and security of these infrastructures than other banks that are not selected for this study.

The method applied to get the practitioners from the organisation is purposive or judgmental sampling, which is a type of non-probability sampling technique in which the researcher selects the units to be observed on the basis of his or her own judgment about which ones will be the most useful or representative (Bless \& Higson-Smith, 2004, pp. 86 - 93).

Table 2: Research participants targeted sample

\begin{tabular}{|l|l|l|l|}
\hline$N^{\circ}$ & BANK & PARTICIPANTS & $\begin{array}{l}\text { DATA COLLECTION } \\
\text { TECHNIQUE }\end{array}$ \\
\hline 01 & A BANK & Three & Semi-structured interview \\
\hline 02 & B BANK & Two & Semi-structured interview \\
\hline 03 & C BANK & One & Semi-structured interview \\
\hline 04 & D BANK & Zero & - \\
\hline
\end{tabular}

A total of six practitioners in ICT frameworks at three different banks constituted the sample for this study.

Considering the information in Table 2, the four banks constituted the $100 \%$ base of participants; the participation rate was 75\% (3 x $100 / 4)$. One bank (D Bank) was part of a restructuring process during the data collection and, therefore, was unable to participate. 


\section{Necessity for Integrated Framework}

With the view that ICT within an organisation should be regarded as an integrated infrastructure that combines direct and indirect resources (Araya et al., 2007), so is the necessity of its management. This is especially true in an industry that intensely relies on ICT infrastructure for its operations, such as the banking industry that connects internal and external customers nationally and internationally. The integrated framework should be able to address not only the direct technological part of ICT infrastructure, but also other elements that contribute to ICT success such as the objectives and vision of the organisation that dictate the ICT strategies. The latter allows the section of ICT Management Frameworks that guides the organisation to assess and manage its internal ICT infrastructure and allows the assessment of different partners that the organisation transacts with.

\section{Summary of Findings}

ICT Management Frameworks benefit banking organisations in different ways, and their applications depend on the individual bank's understanding. For example, one bank observed has gone on to create its own framework by combining different best practices from key ICT management frameworks such as ITIL, COBIT, and CMM.

In general, through this study the researcher has observed that:

- There is diversification in the use of ICT Management Frameworks to manage ICT infrastructures in the SA banking industry; these include COBIT, ITIL, CMM and CMMI, which are the most used.

- A minority of organisations operating in the SA banking industry think of the integration of best practices found in different frameworks into a single framework for integrated management of ICT infrastructure.

- There is no reference to ISO 17799 in the management of ICT infrastructure from all three banking organisations. The reason for this is that they find it easier to use another security standard such as The Standard of Good practice in Information Security, which is agreed by members of the Information Security Forum as the comprehensive best practice, but customise it with reference to ISO 17799 standard for internal use.

- The role played by individual frameworks depends on each bank's own needs and differs greatly between the banks. As a result of these differences, the benefits are measured according the individual bank's purpose of framework implementation.

\section{Exploring an Integrated ICT Management Framework}

Among participating organisations, only one organisation has created a single framework for managing ICT. However this framework addressed technical factors that are related to ICT infrastructure. Capabilities supporting ICT such as presented below are excluded from the framework:

- Human factors, such as training and development;

- Management practices and culture in ICT management; and

- Business objectives that shape ICT objectives and orientation.

Failure to incorporate these elements in ICT management may create inconsistency in recovering from incidents. The failure of ICT during the operations or in sustaining business objectives is not necessarily technological driven but also includes incompetence or lack of required skills, organ- 
isational culture in ICT adoption and development, and the link between business and ICT efforts. Therefore, including these elements can create an effective integrated view of ICT and organisational resources.

To the question of elements of focus that need to be considered when developing an ICT Management Framework the following elements have been presented by the participants:

- Understanding business;

- Understanding business process;

- $\quad$ The infrastructure needed;

- Development tools;

- Service management;

- Security;

- Integration; and

- Consideration business requirement for the bank, such as 24 hours business operations as the Internet banking is to be taken in consideration.

To the above-mentioned elements, other important elements can be added such as:

- Business objectives that direct the efforts of the ICT;

- Business stakeholders who need to be linked to the organisational ICT infrastructure;

- Management practices in managing organisational and ICT efforts, such as control and monitoring of ICT operations, policies, change management, measurements methods and metrics, and adoption of best practices;

- Technological infrastructure in general; and

- Integration practices.

After considering the above elements, the following framework presented in Figure 1, was conceptualised. This framework includes different core elements of focus and related best practices attached to each from various frameworks. 


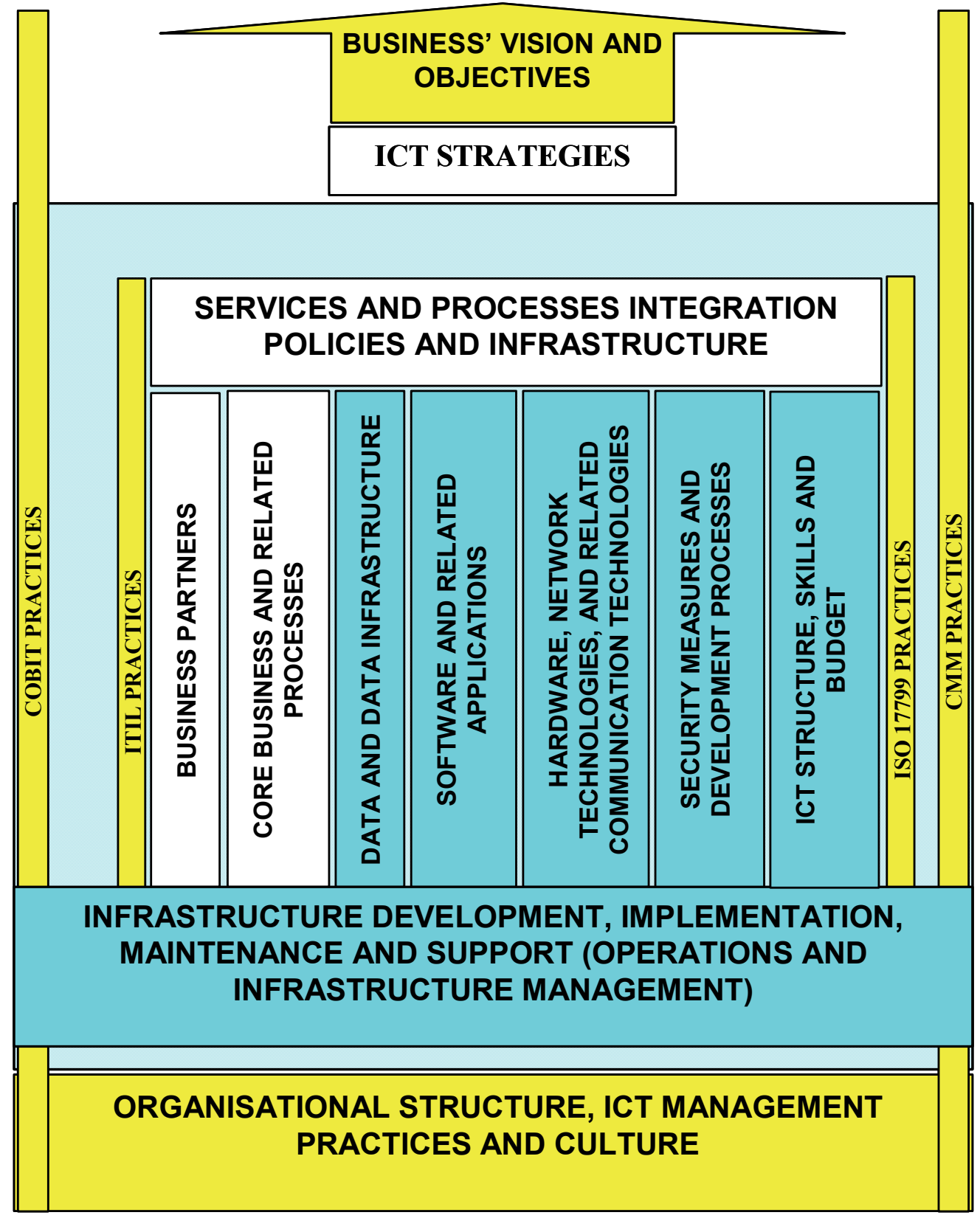

Legend

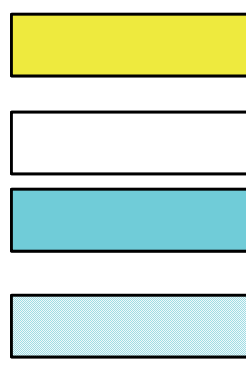

Organisational aspects

Organisational and technical aspects

Technical aspects

Technical area for frameworks

Figure 1: Elements of consideration when developing ICT Management Framework 
Figure 1 can be explained as follows:

- The adoption of ICT management best practices or frameworks is a managerial task.

- Business's vision and objectives are the reason for business to implement the ICT infrastructure. These frameworks are the starting point for ICT strategies, and also the selection of ICT Management Frameworks.

- COBIT and CMM best practices are adopted to manage the business activities in general, not only the technical aspects of ICT infrastructure.

- $\quad$ ITIL and ISO 17799 are the technical frameworks that help the management of ICT infrastructure, from the development to operations. An organisation still needs COBIT and CMM even in the technical part of the ICT.

- Organisational structure, ICT management practices, and culture are the important elements of consideration and the basis on which the adoption and development of ICT Management Frameworks should focus. If the culture, structure, and ICT practices does not allow for innovation and adoption of best practices, the implementation of ICT Management Frameworks will not be a successful project.

- When developing and implementing ICT Management Frameworks, the ICT department needs to address issues related to:

- Business partners, which include customers, suppliers, retailers, and other stakeholders who have access to organisational ICT infrastructure on site or using remote access (this includes even contractors);

- Core business and related processes; this includes the understanding of the organisational activities and processes to complete them;

- Data and data infrastructure; it includes the organisation of data used for business purpose, and infrastructure used to capture, store, manage, publish, archive, and remove the data;

- Software and related applications used; it includes the understanding of business applications (standard and special purpose) software management practices used to process the business information;

- Hardware, network, and related communication technologies; these look at the hardware side of equipment used in processing and transmission of information across the stakeholders;

- Security measures and related development processes; the security in banking industry is a major concern. As such, addressing security issues starts from the development process (each phase) to daily management of ICT, to ensure that risks are if not totally removed, but minimised at low rate of occurrences;

- ICT structure, ICT personnel skills, and budget adoption.

- Organisational structure, culture, and ITC management practice are the elements that stimulate organisations to adopt best practices; these include the skills of dealing with resistance as employees tend to avoid technological innovations as they feel that their physical and intellectual knowledge will be less required as a consequence of losing their positions. They are also the driving forces behind the innovation and adoption of best practices. 
- Measures and strategies on ICT infrastructure development, implementation, maintenance, and support during operations are of great importance. It is required for banks to deliver their services 24 hours a day or ensure quick recovery if an incident occurs; these measures will help to develop action plans to ensure continual delivery of information.

- Finally integrating all these elements to converge to sustainability and achievement of business objectives is of great concern when developing and implementing a single ICT Management Framework, especially when collecting best practices from different sources.

The flow of information to arrive at integrated ICT management can be found in the value diagram presented in Figure 2. This diagram is self explanatory with the different components feeding the "integration practices". The use of specific ICT management best practices will be determined by specific organisational needs and skills. 


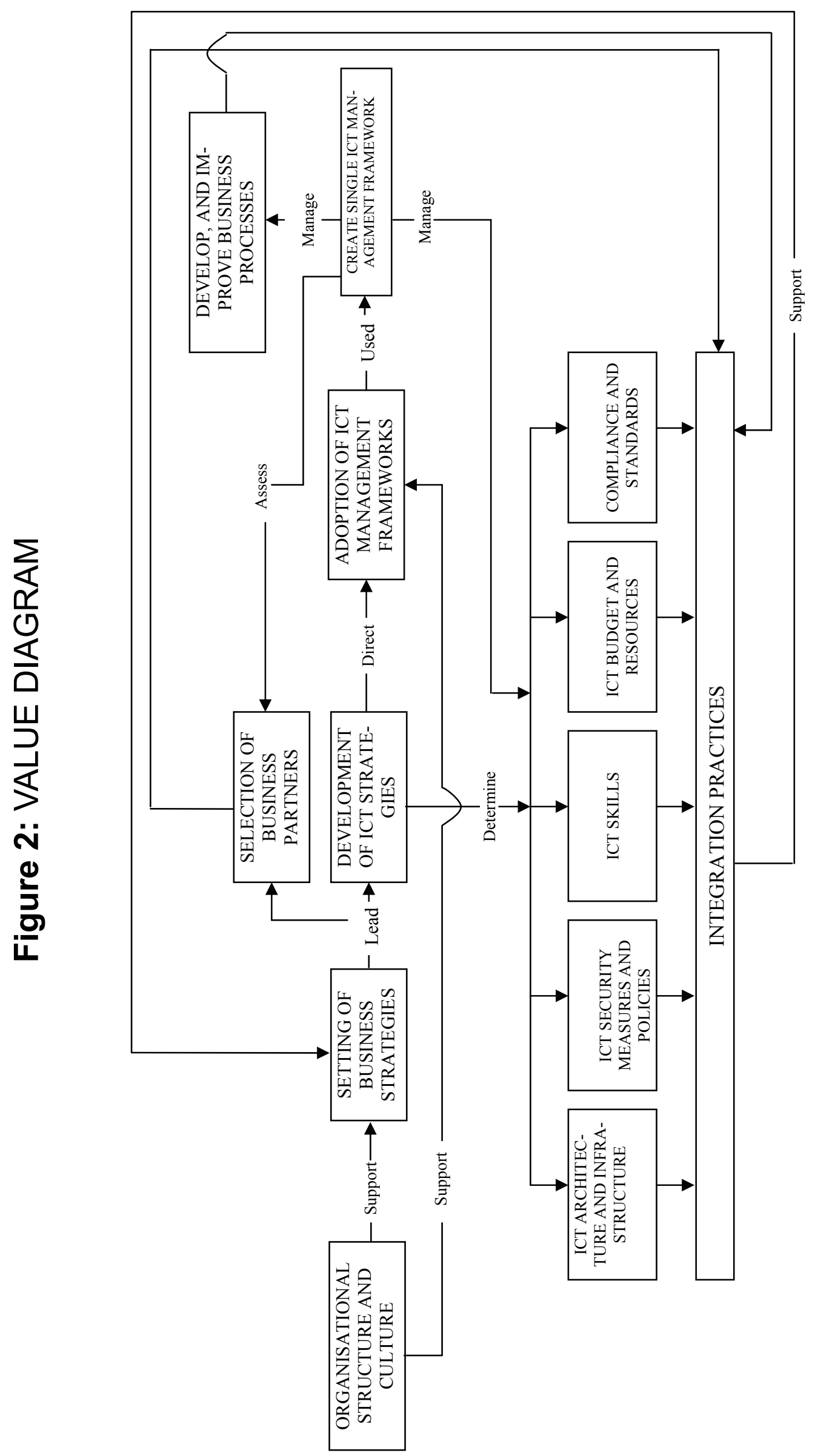




\section{Value of this Study}

The conceptual frameworks presented in Figures 1 and 2 are valuable to the practitioners and banks who participated, in different ways:

- Firstly, it allows them to identify the core elements that identify different core components that they have to identify, collect, and effectively manage to ensure their focus when implementing ICT Management Frameworks;

- Secondly, it helps the banks understand that ICT frameworks are not standalone components in managing ICT infrastructure, but needs to be aligned with other components of the organisation such as management practices, culture, and business objectives to ensure better results in managing ICT.

As mentioned by Thiadens (2005, p. 362), the application of ICT should contribute to the objectives of an organisation. ICT contributes to the achievement of these objectives as it enables efficient and effective working procedures. The use of ICT is also able to support the production of new products and/or services or improve control of the organisation or the group of organisations of which it is part.

\section{Conclusion}

This article addresses the question of ICT Management Frameworks usage in the South African (SA) major commercial banking organisations and explores a framework that integrates different major components that need to be considered when developing a framework.

The use of ICT Management Frameworks in managing ICT infrastructure by commercial banks is not a new topic, but the integration of various best practices addressing an integrated ICT infrastructure is. The integrated framework will facilitate the creation of a holistic view for managing an integrated ICT infrastructure that can allow for a simple and holistic view in managing ICT infrastructure to minimise cost in preventing repetitive efforts of separating different frameworks and allow for the consideration of other ICT non-technical elements.

The success of the organisation in the adoption of ICT infrastructure is not just a question of the technology itself, but how effectively the organization manages the ICT infrastructure and aligns it with its business objectives. This includes the adoption of best practices presented in different ICT Management Frameworks and applies the infrastrucutre in an integrated way.

\section{References}

7Safe. (2007). What is ISO 27001 / iso 17799. Retrieved 29/09/2007 from: http://www.7safe.com/iso27001_iso177992.html

Araya, S., Chaparo, J., Orero, A., \& Joglar, H. (2007). An integrative view of IS/IT and organizational resources and capabilities. Issues in Informing Science and Information Technology, 4, 629-639. Retrieved 25/10/2007 from http://proceedings.informingscience.org/InSITE2007/IISITV4p629639Aray343.pdf

Barton, R. (2003). Global IT management: A practical approach. Great Britain: Wiley.

Best Management Practice. (2007). Service management - ITIL (IT Infrastructure library). Retrieved 29/09/2007 from: http://www.best-management-practice.com/IT-Service-Management-ITIL

Blalock, B. (2005). Information management: The key to success in 2006. Retrieved 17/11/2007 from: http://www.techlinks.net/Editorial/EditorialColumns/tabid/221/ctl/Detail/mid/740/xmid/29635/xmfid/9 $\underline{\text { Default.aspx }}$ 
Bless, C. \& Higson-Smith, C. (2004). Fundamentals of social research method: An African perspective (3rd ed.). Cape Town: Juta.

Caruso, J. B. (2003). Information technology security policy: Keys to success. Center for Application Research, Bulletin volume 2003, Issue 23. Retrieved 17/11/2007 from: http://www.educause.edu/ir/library/pdf/ERB0323.pdf

Cordis. (2007). The European technology platforms (ETPs) and the future Internet. Retrieved 17/11/2007 from: http://cordis.europa.eu/fp7/ict/programme/publications1/books/futint/fi35-etps_en.html

Hornby, A. S. (2000). Oxford advanced learner's dictionary of current English (6th ed.). China: Oxford University Press.

IT Governance Institute. (2004). IT control objectives for Sarbanes-Oxley: The importance of IT design, implementation and sustainability of internal control over disclosure and financial reporting. Retrieved 25/07/2006 from: http://www.isaca.org/Content/ContentGroups/Research1/Deliverables/IT_Control_Objectives_for_Sar banes-Oxley 7july04.pdf

IT Governance Institute (2005). Aligning COBIT, ITIL and ISO 17799 for business benefit: A management briefing from ITGI and OGC. Retrieved 25/10/2007 from: http://www.nysforum.org/documents/pdf/itil-6-6-06/AligningCOBITITIL.pdf

IT Governance Institute. (2007). Cobit 4.1 excerpt. Retrieved 16/08/2007 from: http://www.isaca.org/ATMemplate.cfm?Section=Downloads\&Template=/ContentManagement/Conten $\underline{\text { tDisplay.cfm\&ContentID }=34172}$

Lucas, Jr. H. C. (2005). Information technology: Strategic decision making for managers. USA: John Wiley \& Sons.

Orange Tree Projects Solutions. (2007). The CMMI benefits. Retrieved 29/09/2007 from: http://www.otps.nl/English/QuickScan/Voordelen.html

Thamhain, H. J. (2005). Management of technology: Managing effectively in technology-intensive organisations. USA: John Wiley \& Sons.

Thiadens, T. (2005). Manage IT: Organising IT demand and IT supply. The Netherlands: Springer.

Turban, E., Rainer Jr, R. K. \& Potter, R. (2005). Introduction to information technology (3rd ed.). USA: John Wiley \& Sons.

Welman, J. C. \& Kruger, S. J. (2005). Research methodology (2nd ed.). Cape Town: Oxford University Press.

White, B. (2002). Writing your MBA dissertation. U.K: Thomson.

\section{Bibliographies}

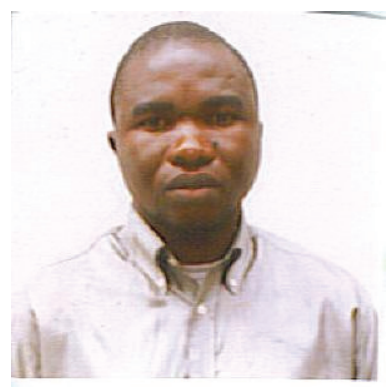

Mukenge Simon Tshinu is a visiting student from Democratic Republic of Congo (DRC), Masters candidate in the Business Information Systems (BIS) department, Faculty of Information and Communication Technology (ICT), at Tshwane University of Technology (TUT), Pretoria, South Africa. His research interests include ICT management frameworks, IT project management, and knowledge management. 


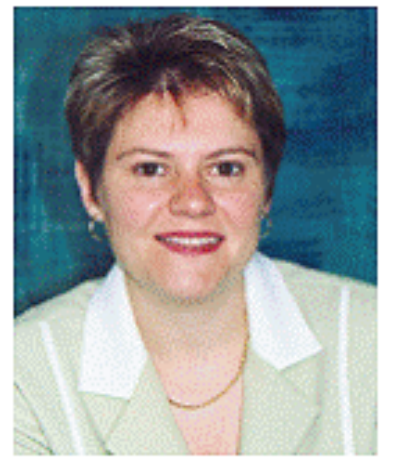

Prof Marlien Herselman is an Associate Research Professor of the Faculty of Information and Communication Technology. In this capacity, she assists lecturers and postgraduate students in research projects, National Research Foundation (NRF) projects, in writing research articles, and in other research-related activities. She obtained her PhD at the University of Pretoria in 1999. Her PhD studies focused on the use of computer games. She is currently busy with research on Technology assessment in rural communities regarding health in South Africa with a National Research Foundation funded project. She was also chairperson of the Faculty Quality Implementation Team from 2003 to 2005. In 2005 she received the prize as Women Researcher of the Year 2004 at Tshwane University of Technology.

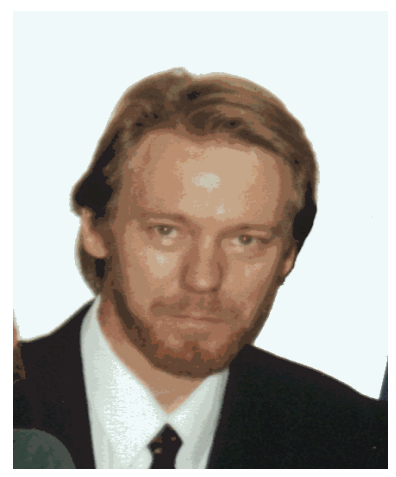

Gerrit Botha is an independent consultant practicing the art and science of enterprise and IT strategy and architecture. He promotes the concept of business capabilities and has successfully developed and implemented several strategies in the public and private sectors, using such an approach.

He lectures on the masters program of the Tshwane University of Technology and has published several articles and conference proceedings on the subject of "value innovation" which is also referenced internationally. 